\title{
Peanut aspiration in an adult
}

\author{
Samuel C.L. Leong*, Kaleelullah S. Farook
}

Accident and Emergency Department, University Hospital Aintree, Liverpool L9 7AL, UK

Received 18 April 2004; accepted 20 May 2004

\section{KEYWORDS}

Tracheo-bronchial;

Aspiration;

Foreign body
Summary We present a case history of a 34-year old adult who aspirated a peanut. Peanut inhalation is a well-recognized condition in children, but is rare in adults. Diagnosis is often difficult and requires a high index of clinical suspicion. A brief review of the literature is presented.

(c) 2004 General Practice Airways Group. Published by Elsevier Ltd. All rights reserved.

\section{Case report}

A 34-year old woman was referred to the Emergency Department by her general practitioner. Shel presented with a three day history of a gradually worsening cough with occasional expectoration. She had suffered a choking incident when she was eating salted peanuts three days earlier. There were no symptoms of dyspnoea, chest pain or haemoptysis. She had never smoked and had no significant past medical history.

On examination, she looked comfortable with no evidence of respiratory distress. Her temperature, pulse and respiratory rate were within normal limits. The only positive finding was the presence of prominent inspiratory crackles and a slight wheeze over the right lower zone on auscultation.

Chest radiography was unremarkable with no signs of a foreign body. There was no evidence of hyperexpansion or atelectasis. The patient was referred urgently to the respiratory physicians. Flexible bronchoscopy revealed the presence of half a peanut lodged in the right intermediate bronchus. The peanut was removed with a snare. Residual small white flecks of the foreign body were removed

*Corresponding author. Present address: 34A Upper Parliament Street, Liverpool L8 1TE, UK. Tel.: +44 1517085147.

E-mail address: Icheel@doctors.org.uk (S.C.L. Leong). with a biopsy forceps. She made an uneventful recovery and was discharged the following day.

\section{Discussion}

Aspirated foreign body (AFB) is one of the leading causes of accidental death in children younger than 4 years [1]. It is, however, much less common in adults [2]. Limper and Prakash conducted a retrospective study at the Mayo Clinic over 33 years and found only 60 adults to have aspirated a foreign body [3]. While peanut aspiration is a well-recognized presentation in children, it is exceptional in adults $[4,5]$. Some authors have quoted incidence of peanut aspiration in children to be as high as $31 \%$ to $46 \%$ [6]. A 20-year comparative study into the incidence of AFB between adults and children found only one case of peanut aspiration in an adult compared to 39 in children [6].

The laryngeal reflex normally protects the lower airway from aspiration. In adults, aspiration can occur if this reflex is impaired - for example, by stroke, alcohol intoxication, sedation and laryngectomy. Clinical presentation of AFB ranges from there being no symptoms to severe respiratory distress, depending on the type, size, and location of the foreign body. The diagnostic clinical triad described for pediatric foreign body aspiration is wheezing, coughing, and decreased 
breath sounds [4]. In contrast, adults normally present with non-specific signs and symptoms such as chronic cough, haemoptysis, fever and dyspnoea [5]. Other symptoms described in adults included stridor, cyanosis, tachypnoea, intercostal retraction, vomiting and hoarseness. Barhaloo et al. [6] studied a cohort of 112 patients and found that 48 patients (49\%) had the 'Penetrating Syndrome' which was defined as a sudden onset of choking and intractable cough with or without vomiting.

Plain radiography is a frequent first-line investigation $[3,7]$. Possible findings of AFB include atelectasis, air trapping, consolidation or a radio-opaque foreign body. Normal radiological findings occur more commonly, ranging from $6 \%$ to $80 \%$ [8]. In a patient with a high index of clinical suspicion a normal chest film, (as occurred with this case), does not rule out the possibility of AFB [9]. Computerised tomography (CT) scans can also be used. Some authors have suggested $\mathrm{CT}$ as being the initial imaging modality for diagnosis of suspected AFB in adults [10].

Definitive treatment of AFB is its removal. Flexible bronchoscopy remains the preferred method, although rigid bronschoscopy is also used [11]. The successful use of the flexible bronchoscope is operator-dependent. It is essential to explore the entire bronchial tree thoroughty to search for resid ual fragments $[3,6,7]$. Eodgment is more common in the right bronchus as the right bronchial tree is wider and more vertical than the left. Thoracotomy is generally the last option $[3,7]$.

Thus, the single most important diagnostic factor leading to discovery of AFB is a high clinical index of suspicion. Although AFB is frequently suspected in children with acute or recurrent pulmonary symptoms, it is rarely considered in adults. Consequently, time to diagnosis of AFB in adults has been shown to be longer than in children $[3,6,7]$. Occult foreign body in adults can remain undetected for years, leading to erroneous diagnosis of asthma, bronchitis or chronic pneumonia [12].

\section{Conclusion}

Aspiration of tracheo-bronchial foreign bodies occurs more commonly in children, but under certain circumstances, it can occur in adults. Physical examination is usually non-specific and may not help in diagnosis. Negative-imaging studies do not exclude the presence of a foreign body. The most important diagnostic factor is a high clinical index of suspicion. A clear history of an aspiration event should never be ignored.

\section{References}

[1] Mantel K, Butenandt I. Tracheobronchial foreign body aspiration in childhood: a report on 224 cases. Eur J Pediatr 1986;145:221-6.

[2] D'Amore A, Hewson GC. The management of acute upper airway obstruction in children. Current Paediatrics 2002;12:17-21.

[3] Limper AH, Prakash UBS. Tracheobronchial foreign bodies in adults. Ann Intern Med 1990;112:604-9.

[4] Muth D, Schafermeyer RW. All that wheezes. Pediatr Emerg Care 1990;6:110-2.

[5] Chen C-H, Lai C-L, Tsai T-T, Lee Y-C, Perng R-P. Foreign body aspirations into the lower airway in Chinese adults. Chest 1997;112(1):129-33.

[6] Barharloo F, Veyckemans F, Francis C, Biettlot M-P, Rodenstein DO. Tracheobronchial foreign bodies: Presentation and management in children and adults. Chest 1999;115(5):1357-62.

[7] Lan R-S. Non-asphyxiating tracheobronchial foreign bodies in adults. Eur Respir J 1994;7:510-4.

[8] Mu LC, Sun DQ, He P. Radiological diagnoses of aspirated foreign bodies in children: review of 343 cases. J Laryngol Otol 1990;104:778-82.

[9] Kavanagh PV, Mason AC, Muller NL. Thoracic foreign bodies in adults. Clinical Radiology 1999;54:353-60.

[10] Zissin R, Shapiro-Feinberg M, Rozenman J, Apter S, Smorjik $\mathrm{J}$, Hertz M. CT findings of the chest in adults with aspirated foreign bodies. Eur Radiol 2001;11(4):606-11.

[11] Debeljak A, Sorli J, Music E, Kecelj P. Bronchoscopic removal of foreign bodies in adults: experience with $62 \mathrm{pa}$ tients from 1974-1998. Eur Respir J 1999;14:792-5.

[12] Hornick PJ, Wallis J, Edmondson SJ. Inhaled foreign bodies in the adult as a cause of unresolved pneumonia. $\mathrm{Br} \mathrm{J}$ Hosp Med 1990;44(3):214.

Available online at www.sciencedirect.com

science@direct. 